\title{
Evaluation of Chemical Parameters in Soft Mold-Ripened Cheese During Ripening by Mid-Infrared Spectroscopy
}

\author{
S. T. Martín-del-Campo, ${ }^{*}$ D. Picque, ${ }^{1}$ R. Cosío-Ramírez,† and G. Corrieu* \\ *Unité Mixte de Recherche Génie et Microbiologie des Procédés Alimentaires, Institut National de la Recherche Agronomique, \\ Agro Paris Tech, F-78850 Thiverval-Grignon, France \\ †Postgrado en Procesos Biotecnológicos CIATEJ-CUCEI, Universidad de Guadalajara, Centro de Investigación y Asistencia en Tecnologia \\ y Diseño del Estado de Jalisco, A. C. (CIATEJ) Avenida Normalistas 800, Sector Hidalgo, Col. Colinas de la Normal, Guadalajara, \\ Jalisco, 44270, México
}

\begin{abstract}
The suitability of mid-infrared spectroscopy (MIR) to follow the evolution throughout ripening of specific physicochemical parameters in Camembert-type cheeses was evaluated. The infrared spectra were obtained directly from raw cheese samples deposited on an attenuated total reflectance crystal. Significant correlations were observed between physicochemical data, $\mathrm{pH}$, acid-soluble nitrogen, nonprotein nitrogen, ammonia $\left(\mathrm{NH}_{4}^{+}\right)$, lactose, and lactic acid. Dry matter showed significant correlation only with lactose and nonprotein nitrogen. Principal components analysis factorial maps of physicochemical data showed a ripening evolution in 2 steps, from d 1 to $d 7$ and from d 8 to $d 27$, similar to that observed previously from infrared spectral data. Partial least squares regressions made it possible to obtain good prediction models for dry matter, acid-soluble nitrogen, nonprotein nitrogen, lactose, lactic acid, and $\mathrm{NH}_{4}{ }^{+}$values from spectral data of raw cheese. The values of 3 statistical parameters (coefficient of determination, root mean square error of cross validation, and ratio prediction deviation) are satisfactory. Less precise models were obtained for $\mathrm{pH}$.
\end{abstract}

Key words: mid-infrared spectroscopy, chemical parameter, Camembert cheese ripening, principal components analysis

\section{INTRODUCTION}

Traditionally, cheese ripening evolution is evaluated by measuring the substrate and by-products of major biochemical phenomena, principally proteolysis and glycolysis, as well as physical parameters such as $\mathrm{pH}$ and DM. Different reference physicochemical methods are used (Ardö and Polychroniadou, 1999). Thus, prote-

Received October 10, 2006.

Accepted February 8, 2007.

${ }^{1}$ Corresponding author: picque@grignon.inra.fr olysis is evaluated by measuring the nitrogen content in different fractions such the water-soluble N (WSN), acid-soluble nitrogen (ASN), NPN, ethanol-soluble N, and ethanol-insoluble N (Christensen et al., 1991). The glycolysis phenomenon is evaluated by lactose consumption and lactic acid evolution. These methods have been described for different cheeses such as Camembert (Engel et al., 2001; Leclercq-Perlat et al., 2004), Ragusano (Fallico et al., 2004), and Prato (Gorostiza et al., 2004).

To improve the knowledge of cheese ripening, the use of different separation techniques such as HPLC or electrophoresis in combination with multivariate statistical techniques such as principal components analysis (PCA), factorial analysis, hierarchical cluster analysis, and partial least squares (PLS) regression has been reported (Pripp et al., 1999; Karoui et al., 2003; Poveda et al., 2004). The utility of these methods to assess the cheese ripening evolution has been demonstrated. Nevertheless, they are time-consuming, destructive, and sometimes expensive; and consequently, their use to follow cheese-ripening kinetics is limited. There is interest in developing fast, accurate, easy to use, and low-cost analytical methods to characterize cheese ripening.

Fourier transform infrared spectroscopy (FTIR) in combination with multivariate statistical techniques makes it possible to obtain specific information about different parameters simultaneously in a direct, reliable, and rapid way. Its use has been reported before for milk and dairy products, and the absorption bands have been identified and attributed to chemical groups (McQueen et al., 1995; Chen et al., 1998; Etzion et al., 2004). Recently, Rodriguez-Saona et al. (2006) showed the ability of attenuated total reflectance/infrared spectroscopy to provide good estimations of moisture, fat, and protein of Swiss cheese. Good PLS models have been developed to predict selected free AA concentration from near infrared (NIR) spectra of Norwegian cheeses (Skeie et al., 2006). Nonprotein N and WSN 
contents and $\mathrm{pH}$ are predicted with a good accuracy from mid-infrared (MIR) spectra of European Emmental cheeses produced during summer (Karoui et al., 2006c) and during winter (Karoui et al., 2006d). Fat and total nitrogen (TN) contents were estimated with lower precision but the results could be improved by the use of NIR spectra (Karoui et al., 2006a). In a preliminary study, Karoui et al. (2006b) showed that DM, TN, and WSN of soft cheese were best predicted with UV-NIR spectroscopy in comparison with MIR spectroscopy.

As seen above, the ability of those methods to correlate the infrared signal with different physicochemical parameters has been demonstrated. Nevertheless, those works were developed in ripened cheeses but never during the progress of the ripening, at time when this information on the composition of cheeses would be very useful to help the cheese maker monitor ripening.

The objective of this work was to evaluate the suitability of FTIR to follow the evolution of specific physicochemical parameters throughout ripening of soft moldripened Camembert-type cheeses. Each sample was analyzed by attenuated total reflectance (ATR); different physicochemical parameters as $\mathrm{pH}, \mathrm{DM}, \mathrm{ASN}, \mathrm{NPN}$, $\mathrm{NH}_{4}{ }^{+}$, lactose, and lactic acid were evaluated by traditional methods. The physicochemical evolutions were described by PCA and their correlations with spectral data were evaluated by PLS.

\section{MATERIALS AND METHODS}

\section{Cheese Production}

For this study, 2 trials of 45 units of $360 \mathrm{~g} \pm 20 \mathrm{~g}$ of mold-ripened soft cheeses were carried out on a pilot scale using Camembert cheese technology, as previously described by Leclercq-Perlat et al. (2004). After brining, the cheeses were transferred to a previously sterilized ripening chamber $\left(1 \mathrm{~m}^{3}\right)$ and kept at $13 \pm 1^{\circ} \mathrm{C}$ and $85 \pm 2 \%$ relative humidity for $24 \mathrm{~h}$. After $24 \mathrm{~h} \mathrm{(d}$ 2 ), relative humidity was increased to $95 \pm 2 \%$ and kept at this level until d 15 . On d 15, the cheeses were wrapped and left to ripen at $4^{\circ} \mathrm{C}$ and unknown humidity until d 27.

\section{Sampling}

The sampling procedure was the same for both trials. One whole cheese was removed daily between $\mathrm{d} 1$ and 8. After $\mathrm{d} 8$, the physicochemical and biochemical kinetics are slower (Leclercq-Perlat et al., 2004); therefore, 1 sample per day was analyzed on d 10,15, 17, 20, and 27 . For these analyses, the sample rinds ( $2 \mathrm{~mm}$ thick) were removed and the interiors of the cheeses were sliced horizontally to obtain 2 sections. The core was the 8-mm-thick central portion and the underrind was the section between the rind and the core. During ripening, cheese undergoes considerable modification of texture. The curd is firm and brittle at the beginning of ripening and later becomes soft. Softening is visible in the underrind and gradually extends toward the center.

\section{Physicochemical Analysis}

The $\mathrm{pH}, \mathrm{DM}$, lactose, and lactic acid were determined as described by Leclercq-Perlat et al. (1999). The nitrogen fractions, ASN, NPN, $\mathrm{NH}_{4}{ }^{+}$, and TN, were evaluated as described by Leclercq-Perlat et al. (2000). These physicochemical parameters were analyzed in the underrind samples. Lactose and lactic acid content were additionally evaluated in the core samples.

\section{Infrared Spectroscopy}

The 2 cheese sections were directly analyzed by infrared spectroscopy. The sample spectra were recorded in the 4,000 to $650 \mathrm{~cm}^{-1}$ region with a Magna IR-750 purged spectrometer (Thermo Electron, Madison, WI) equipped with a DTGS detector, an Ever-Glo source, and a horizontal $\mathrm{ZnSe}\left(45^{\circ}\right.$ and 12 reflections) ATR accessory (all from Thermo Electron). Cheese slices with an approximate mass of $10 \mathrm{~g}$ were placed in the ATR bowl and covered without any supplementary pressure. Each sample spectrum was the average of 32 scans at $4 \mathrm{~cm}^{-1}$ resolution (data spacing $1.928 \mathrm{~cm}^{-1}$ ) and the ATR crystal spectrum was subtracted from them. The Happ-Gentzel apodization was used. To verify the consistency of spectrometer measurement over time, Val Q software (Thermo Electron) was used to measure and evaluate the peak-to-peak noise and the root mean square noise at several wavenumbers.

The water content of the samples changes during the ripening and the water spectrum presents an important peak in the amide zone that masked the protein signal. Therefore, it was necessary to subtract the water absorbance to take into account these changes and to highlight the amide peaks. The water spectra were subtracted and the base line corrected using OMNIC 4.1a software (Thermo Electron). The water subtraction was carried out adapting the methodology described by Powell et al. (1986) and Dousseau et al. (1989). The subtraction factor was calculated taken into account only the area between 2,300 and $1,900 \mathrm{~cm}^{-1}$.

Spectral data were input to multivariate process in several forms: after baseline correction performed manually in 6 points $(3,000,2,850,1,800,1,700,1,490$, and $950 \mathrm{~cm}^{-1}$ ), and after the first or second derivative of the spectra using the Savitzky-Golay method (4 data points each side). The baseline correction was performed to 
Table 1. Physicochemical parameter values of cheeses used in the calibration and validation set for the partial least squares regression

\begin{tabular}{|c|c|c|c|c|c|c|c|c|c|c|}
\hline \multirow[b]{2}{*}{ Parameter } & \multicolumn{5}{|c|}{ Calibration data } & \multicolumn{5}{|c|}{ Validation data } \\
\hline & $\mathrm{n}$ & Maximum & Minimum & Mean & SD & $\mathrm{n}$ & Maximum & Minimum & Mean & SD \\
\hline $\mathrm{pH}$ & 17 & 7.86 & 4.57 & 6.17 & 1.37 & 8 & 7.80 & 4.66 & 6.15 & 1.43 \\
\hline Acid-soluble $\mathrm{N}, \mathrm{g} / 100 \mathrm{~g}$ of total $\mathrm{N}$ & 17 & 104.13 & 15.82 & 62.53 & 37.27 & 8 & 99.87 & 16.22 & 60.12 & 39.23 \\
\hline NPN, g/100 g of total N & 17 & 50.00 & 3.13 & 25.30 & 18.33 & 8 & 41.48 & 2.69 & 25.66 & 19.64 \\
\hline $\mathrm{NH}_{4}^{+}, \mathrm{g} / \mathrm{kg}$ of $\mathrm{DM}$ & 17 & 16.31 & 0.46 & 6.03 & 5.41 & 8 & 15.00 & 1.00 & 6.28 & 5.20 \\
\hline Lactose, $\mathrm{mmol} / \mathrm{kg}$ of $\mathrm{DM}$ & 33 & 166.05 & 0.00 & 50.04 & 52.54 & 16 & 105.46 & 0.00 & 41.28 & 39.43 \\
\hline
\end{tabular}

take in account the eventual drift of spectrometric signal between 4,000 and $650 \mathrm{~cm}^{-1}$.

Because the cheese texture was modified throughout ripening, the contact between the cheese and the $\mathrm{ZnSe}$ crystal as well as the depth of penetration of the infrared beam could depend on the analyzed sample. Consequently, the cheese spectra were normalized before carrying out the statistical analysis by dividing each value among the sum of spectrum values (Bertrand, 2000).

\section{Statistical Analysis}

The statistical analyses were carried out using the Statistica software (StatSoft, Paris, France). The analysis of correlation was carried out to evaluate the relations among the physicochemical parameters $(P<0.05)$.

Principal components analysis was applied to the physicochemical data to evaluate their evolution throughout ripening. The PCA made it possible to obtain an overview of the information of the data set by replacing the original variables by a few new variables, the principal components (PC); PC contain almost all the information and are orthogonal among themselves.

The PLS regression was used to establish regression models between the physicochemical data and the spectral data. Partial least squares is a data compression technique that provides good relationships in case of collinearity, as in spectral data, maximizing the covariance between successive PLS scores and the dummy variates. One of the most important issues in PLS regression is to determine the size of the model to describe the significant source of variation, but without overfitting. Therefore, the physicochemical values and sample spectra were split into 2 sets, the calibration set and the cross validation set. Typically, calibration and validation sets may contain two-thirds and one-third of the available observations, respectively (Defernez and Kemsley, 1997). Seventeen samples for pH, DM, ASN, NPN and $\mathrm{NH}_{4}{ }^{+}$and 33 samples for lactose and lactic acid were taken for the calibration set. Eight samples for $\mathrm{pH}, \mathrm{DM}, \mathrm{ASN}, \mathrm{NPN}$ and $\mathrm{NH}_{4}{ }^{+}$and 16 samples for lactose and lactic acid were taken for the validation set. The minimum and maximum values as well as the mean and the standard deviation for these variables are shown in Table 1. The calibration set was used to establish the PLS models, and the cross validation set to fit the model. The number of factors was determined by using the minimum prediction residual error sum of squares (PRESS) value.

The quality of the regression models were evaluated by the coefficient of determination $\left(\mathrm{R}^{2}\right)$, the standard error of calibration (SEC) and the root mean square error of cross validation (RMSECV) defined as

$$
\begin{aligned}
& \mathrm{SEC}=\sqrt{\frac{1}{n-k-1} \sum_{i=1}^{n}\left(y_{i}-\hat{y}_{i}\right)^{2}} \\
& \text { RMSECV }=\sqrt{\frac{1}{n} \sum_{i=1}^{n}\left(y_{i}-\hat{y}_{i}\right)^{2}}
\end{aligned}
$$

where $y_{i}$ is the measured value, $\hat{y}_{i}$ the predicted value, $n$ the sample number, and $k$ the number of PLS factor. According to $\mathrm{R}^{2}$ value, the model is considered good for prediction if $R^{2}$ is $>0.81$ and adequate only for approximate quantitative predictions if $R^{2}$ is between 0.66 and 0.81 (Karoui et al., 2006b).

The ratio prediction deviation (RPD) was calculated by dividing the standard deviation of the data set by the SEC and RMSECV results, respectively. Mouazen et al. (2005) and Karoui et al. (2006b) report that a ratio greater than 2 indicates a good calibration whereas a ratio $<1.5$ indicates incorrect predictions.

\section{RESULTS AND DISCUSSION}

\section{Infrared Analysis}

As an example, normalized FTIR spectra $(3,000$ to $2,800 \mathrm{~cm}^{-1}$ and 1,800 to $950 \mathrm{~cm}^{-1}$ ) of the cheese underrind sampled at $d 1$ and 27 are shown in Figure 1. 


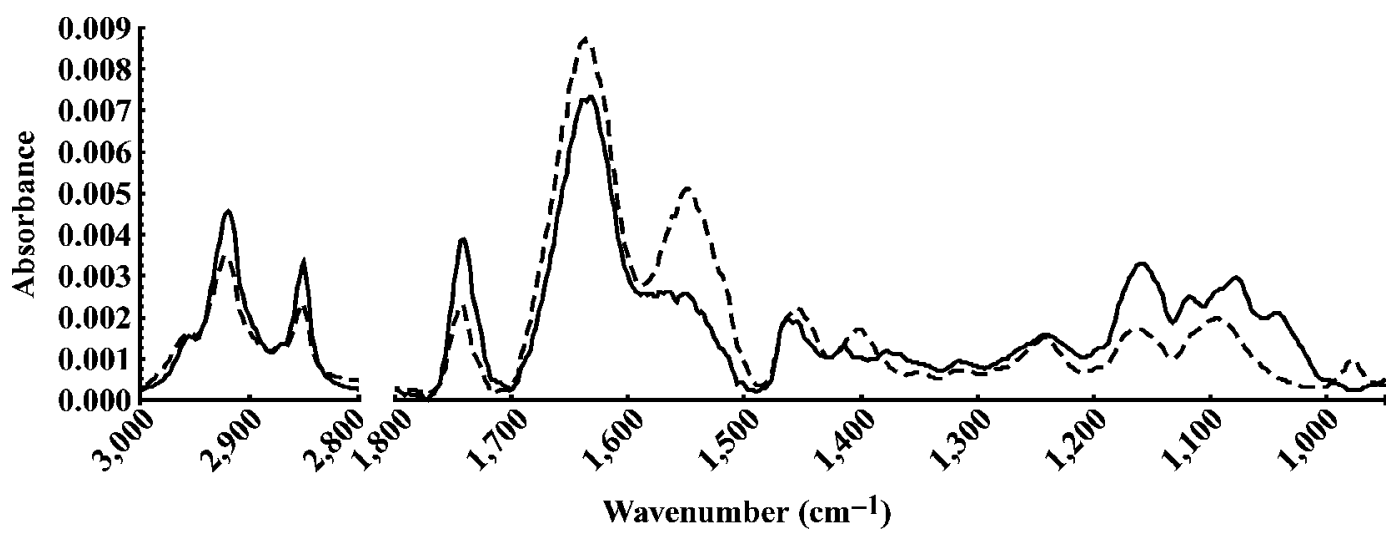

Figure 1. Normalized mid-infrared spectra (3,000 to $2,750 \mathrm{~cm}^{-1}$ and 1,800 to $\left.950 \mathrm{~cm}^{-1}\right)$ of the cheese underrind section. The solid curve indicates data from d 1 and the dashed line, data from $\mathrm{d} 27$.

In the MIR zone, the absorption bands are assigned to fundamental vibrations of functional groups of the molecule. The bands associated with proteins, fats, lactose, and lactic acid are well known and have been described in milks and cheeses. Bands located at 1,096 $\mathrm{cm}^{-1}$ (secondary alcohol $\nu \mathrm{C}-\mathrm{O}$ and $\delta \mathrm{O}-\mathrm{H}$, where $v=$ vibration and $\delta=$ deformation), $1,082 \mathrm{~cm}^{-1}(\delta \mathrm{O}-\mathrm{H})$, and $\sim 1,045 \mathrm{~cm}^{-1}$ (primary alcohol $\nu \mathrm{C}-\mathrm{O}$ ) have been assigned to lactose (Picque et al., 1993; Cadet et al., 2000; Grappin et al., 2000). Organic acids, such as lactic acid, show absorption bands at 1,575, 1,402 (-COO-), and 1,115 $\mathrm{cm}^{-1}(\nu \mathrm{C}-\mathrm{OH})$. The contribution of the nitrogen fractions can be observed in the 1,700 to $1,500 \mathrm{~cm}^{-1}$ spectral region with 2 major bands at $1,550 \mathrm{~cm}^{-1}$ assigned to amide II ( $\delta \mathrm{N}-\mathrm{H}$ and $\nu \mathrm{C}-\mathrm{N}$ ) and at $1,640 \mathrm{~cm}^{-1}$ assigned to amide $\mathrm{I}(\nu \mathrm{C}=\mathrm{O}, \nu \mathrm{C}-\mathrm{N})$. It can also be observed the contribution of the bands at 2,920 and $2,851 \mathrm{~cm}^{-1}$ $\left(-\mathrm{CH}_{2^{-}}\right)$and at 2,954 and $2,871 \mathrm{~cm}^{-1}\left(-\mathrm{CH}_{3}\right)$.

\section{Physicochemical Parameters: Correlations and PCA}

The correlations observed between the physicochemical parameters evaluated are shown in Table 2. Most of the parameters showed significant correlations at a level of $P<0.05$ between them except for DM, which showed correlations only with lactose $(\mathrm{R}=-0.53)$ and NPN ( $R=0.52)$. As expected, lactose and lactic acid showed a positive correlation between them and a negative correlation with the $\mathrm{pH}$ but also with ASN, NPN, and $\mathrm{NH}_{4}{ }^{+}$. Lactic acid was produced from lactose and the increase in $\mathrm{pH}$ was dependent on lactic acid consumption. The nitrogen fractions were highly intercorrelated $(\mathrm{R}>0.87)$. The $\mathrm{pH}$ showed high correlations with all the parameters excepting DM $(R=0.34)$.

These results were consistent with those reported by Leclercq-Perlat et al. (2004) for Camembert-type cheese, by Karoui et al. (2006d) for European Emmental cheeses, and by Fallico et al. (2004) for $\mathrm{pH}$ and nitrogen fractions during Ragusano cheese ripening.

The PCA factorial map and the factor loadings plot for the physicochemical parameters, defined by PC1 and PC3, are shown in Figure 2 ( $a$ and b). These components explained 80.58 and $3.56 \%$ of total variance, respectively. In the factorial map (Figure 2a), an evolution in 2 phases is noted, phase 1 from $d 1$ to 7 and phase 2 from $d 8$ to 20 . On the first axis, the value of the factor coordinates of variables (day of ripening) decreased continuously according to ripening time. On the third axis, they decreased between $\mathrm{d} 1$ and 7 and then increased from $\mathrm{d} 8$ to 27 .

Table 2. Correlation coefficients for the physicochemical variables analyzed on soft mold-ripened cheeses during ripening

\begin{tabular}{|c|c|c|c|c|c|c|c|}
\hline Variable & $\mathrm{pH}$ & Lactose & Lactic acid & ASN & NPN & $\mathrm{NH}_{4}^{+}$ & $\mathrm{DM}$ \\
\hline $\mathrm{pH}$ & 1.00 & & & & & & \\
\hline Lactose & $-0.84^{*}$ & 1.00 & & & & & \\
\hline Lactic acid & $-0.96^{*}$ & $0.77^{*}$ & 1.00 & & & & \\
\hline Acid-soluble N (ASN) & $0.97 *$ & $-0.88^{*}$ & $-0.94^{*}$ & 1.00 & & & \\
\hline NPN & $0.96^{*}$ & $-0.87^{*}$ & $-0.95^{*}$ & $0.96^{*}$ & 1.00 & & \\
\hline $\mathrm{NH}_{4}^{+}$ & $0.88^{*}$ & $-0.71^{*}$ & $-0.93^{*}$ & $0.87 *$ & $0.87^{*}$ & 1.00 & \\
\hline $\mathrm{DM}$ & 0.34 & $-0.53^{*}$ & -0.34 & 0.34 & $0.52^{*}$ & 0.23 & 1.00 \\
\hline
\end{tabular}

$* P<0.05$. 
a)

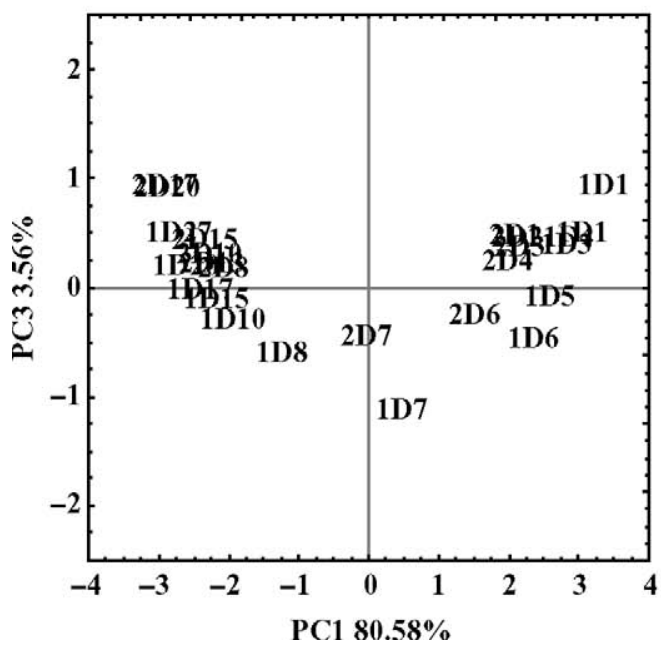

b)

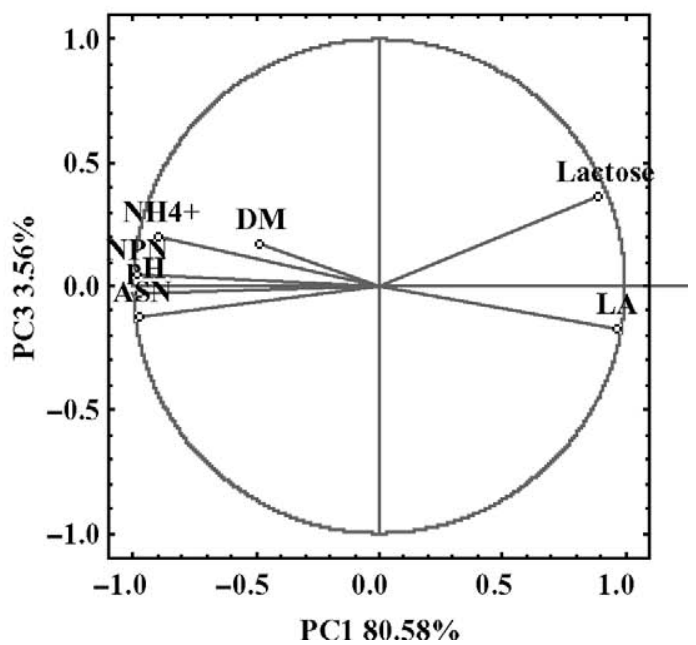

Figure 2. Principal components analysis (PCA) plots of the first 2 principal components, PC1 and PC3: a) factorial map of scores, and b) factor loadings. $\mathrm{XDy}=$ samples code where $\mathrm{x}=$ trial and $\mathrm{y}=$ ripening day; $\mathrm{ASN}=$ acid-soluble $\mathrm{N}$; LA = lactic acid.

As shown in the factor loadings plot (Figure 2b), all of the studied variables except $\mathrm{DM}(\mathrm{R}=-0.486)$ were strongly correlated $(\mathrm{R}>0.89)$ with $\mathrm{PC} 1$. Lactose and lactic acid showed positive correlations $(\mathrm{R}=0.893$ and 0.962 , respectively), whereas $\mathrm{pH}(\mathrm{R}=-0.973), \mathrm{ASN}(\mathrm{R}=$ $-0.976)$, NPN $(\mathrm{R}=-0.989)$, and $\mathrm{NH}_{4}{ }^{+}(\mathrm{R}=-0.895)$ showed negative correlations. Lactose and $\mathrm{NH}_{4}{ }^{+}$were the most correlated variables with $\mathrm{PC} 3$, with $\mathrm{R}=0.33$ and 0.22 , respectively. These observations suggested that PC1 described glycolysis, as revealed by the decrease of lactose and lactic acid concentrations as well as the increase in $\mathrm{pH}$ as a result of lactic acid consumption. These results are consistent with the work of Leclercq-Perlat et al. (2004). These authors described a decrease in lactose in the rind during the first $6 \mathrm{~d}$ of Camembert cheese ripening. In that study, lactic acid concentrations increased during the first $4 \mathrm{~d}$, and then decreased until the end of the ripening (d 27). Additionally, $\mathrm{PC} 1$ described the proteolysis phenomenon, as revealed by the positive correlation between the axes and the nitrogen fractions. Leclercq-Perlat et al. (2004) showed that proteolysis of the soft cheese was negligible during the first $6 \mathrm{~d}$ of ripening. The ASN and NPN indices increased quickly between $\mathrm{d} 6$ and 10 and thereafter remained constant. Ammonia concentrations increased from d 6 to 27.

The PCA of cheese physicochemical parameters showed similar results to those described by Martín del Campo et al. (2007) for the PCA of infrared spectra of the same cheeses. These authors described an evolution of the spectral data in 2 phases linked to lactose in a first phase (from d 1 to 8 ) and to lactic acid and nitrogen fractions in a second phase (from d 8 to 27). This similar- ity and the information contained in the spectra suggest that the spectral data can be correlated with physicochemical values to predict their evolution during the cheese ripening.

\section{Prediction of Physicochemical Values from IR Spectra by PLS Regression}

The PLS regression was applied to evaluate the relationship between the physicochemical values and the infrared spectral responses throughout ripening. Evaluation of the performance of the PLS models is based on the $\mathrm{R}^{2}$, SEC, RMSECV, and the RPD determination for calibration and validation sets (Table 3 ).

For the calibration set, good correlations between the physicochemical values and the infrared spectra were obtained for all the parameters except ASN, if we consider $R^{2}$ and $R P D$ values. The coefficient of determination $\mathrm{R}^{2}$ and the RPD are $>0.81$ and $>2$, respectively. In comparison, prediction of ASN could be considered less good on the calibration set $\left(R^{2}=0.73, R P D=2.01\right)$. The results concerning $\mathrm{pH}$, DM, and NPN have to be considered carefully because the PLS scores were high: 7,11 , and 8 , respectively. The higher the dimensionality of the model, the greater the likelihood of overfitting (Defernez and Kemsley, 1997). However, the difference between the SEC and the RMSECV obtained, respectively, for the calibration and validation sets were not high (Table 3) and suggested that the models were reasonably robust. For $\mathrm{pH}$, the SEC of 0.39 and the RMSECV of 0.38 were considered too high for a good prediction. 
Table 3. Partial least squares regression results using the physicochemical values and cheese mid-infrared spectra $^{1}$

\begin{tabular}{|c|c|c|c|c|c|c|c|c|c|}
\hline \multirow[b]{2}{*}{ Parameter } & \multicolumn{5}{|c|}{ Calibration set } & \multicolumn{4}{|c|}{ Validation set } \\
\hline & $\mathrm{n}$ & Comp. & $\mathrm{R}^{2}$ & SEC & $\mathrm{RPD}$ & $\mathrm{n}$ & $\mathrm{R}^{2}$ & RMSECV & $\mathrm{RPD}$ \\
\hline $\mathrm{PH}^{2}$ & 17 & 7 & 0.94 & 0.39 & 3.51 & 8 & 0.84 & 0.38 & 3.71 \\
\hline $\mathrm{DM}{ }^{2} \mathrm{~g} / 100 \mathrm{~g}$ of cheese & 17 & 11 & 0.99 & 0.53 & 6.95 & 8 & 0.91 & 1.07 & 2.99 \\
\hline Acid-soluble $\mathrm{N},{ }^{2} \mathrm{~g} / 100 \mathrm{~g}$ of total $\mathrm{N}$ & 17 & 3 & 0.73 & 18.5 & 2.01 & 8 & 0.84 & 13.3 & 2.95 \\
\hline $\mathrm{NPN},{ }^{2} \mathrm{~g} / 100 \mathrm{~g}$ of total $\mathrm{N}$ & 17 & 8 & 0.98 & 3.7 & 4.96 & 8 & 0.92 & 6.0 & 3.27 \\
\hline $\mathrm{NH}_{4}^{+}, 2 \mathrm{~g} / \mathrm{kg}$ of $\mathrm{DM}$ & 17 & 2 & 0.91 & 1.80 & 3.01 & 8 & 0.99 & 1.29 & 4.03 \\
\hline Lactose, ${ }^{3} \mathrm{mmol} / \mathrm{kg}$ of $\mathrm{DM}$ & 33 & 6 & 0.97 & 4.9 & 10.7 & 16 & 0.85 & 11 & 3.58 \\
\hline Lactic acid, ${ }^{3} \mathrm{mmol} / \mathrm{kg}$ of DM & 33 & 4 & 0.93 & 47 & 4.00 & 16 & 0.90 & 50 & 3.76 \\
\hline
\end{tabular}

${ }^{1}$ Comp = components; $\mathrm{R}^{2}$ = coefficient of determination; SEC = standard error of calibration; RMSECV = root mean square error of cross validation; $\mathrm{RPD}=$ ratio prediction deviation.

${ }^{2}$ Baseline correction of spectra in 6 points.

${ }^{3}$ First derivative of spectra.

Dry matter, ASN, NPN, lactose, lactic acid, and $\mathrm{NH}_{4}{ }^{+}$ predictions presented satisfactory values $\left(\mathrm{R}^{2}>0.80\right.$, RPD $>2$, and RMSEC close to SEC). The correlations between the measured and predicted values of these 5 physicochemical parameters are shown in Figure 3 (a to f). A good fit was observed between the measured and predicted values for the calibration set and the validation set.

The results obtained for cheeses sampled during the ripening, can be compared with values published for ripened cheeses. The accuracy obtained for $\mathrm{DM}$ and $\mathrm{pH}$ was in agreement with that reported by Karoui et al. (2006b) for commercial soft cheeses. Nevertheless, they mentioned that the PLS models based on spectral data allow a good prediction for these parameters in spite of a RMSEC of 0.16 on the $\mathrm{pH}$ determination. This value can be judged as too high. For the WSN index (WSN/TN), those authors reported a lower accuracy $\left(\mathrm{R}^{2}=0.60, \mathrm{RPD}=1.58\right)$ than that obtained in the present work for ASN. Karoui et al. (2006b) noted that the measurement of this parameter by MIR was useful only to discriminate between high and low concentrations.

The results obtained for NPN index were similar to those reported by Karoui et al. (2006a) in ripened Emmental cheeses of different ages and geographic origins. They reported good calibration for the NPN content $\left(\mathrm{R}^{2}=0.83\right.$ and $\mathrm{RPD}=2.34$ vs. 0.92 and 3.27 in our study, respectively).

With the same type of ATR accessory used in our studies, Rodriguez-Saona et al. (2006) predicted the moisture of Swiss cheese with a RMSECV of 0.5, 2 times lower than that calculated for DM in this study.

The standard regression coefficients of DM, ASN, NPN, lactose, lactic acid, and $\mathrm{NH}_{4}{ }^{+}$over the wavenumber range are shown in Figure 4 (a to f). Information about which wavelengths contributed most to the prediction of physicochemical parameters can be obtained from these plots. The same type of observations can be made from the loading plots. In several cases, assignment of the bands may be made, whereas in other cases, no identification may be made. But, as previously described by Downey et al. (2005) in the prediction of maturity and sensory attributes, considerable structure is present in all of them and differences exist in the relative importance of individual wavelengths. Accordingly, the models developed for the prediction of physicochemical parameters are expected to provide realistic results.

The regression coefficient distribution for DM (Figure 4a) shows that the 1,320 to $1,220 \mathrm{~cm}^{-1}, 1,500$ to 1,400 $\mathrm{cm}^{-1}, 1,730$ to $1,680 \mathrm{~cm}^{-1}$, and 3,000 to $2,900 \mathrm{~cm}^{-1}$ spectral bands are the most efficient regions. The interpretation is difficult for the first 2 regions. The other regions could be attributed to carboxyl (-COO-) as well as the methyl $\left(\mathrm{CH}_{3}\right)$ and methylene $\left(\mathrm{CH}_{2}\right)$ groups.

For ASN, Figure $4 \mathrm{~b}$ shows the characteristic bands of carboxyl (1,800 to $\left.1,700 \mathrm{~cm}^{-1}\right)$, amide I (1,700 to 1,600 $\left.\mathrm{cm}^{-1}\right)$, and amide II $\left(1,600\right.$ to $\left.1,500 \mathrm{~cm}^{-1}\right)$, as expected. An opposition between the amide bands was observed as reported by Karoui et al. (2006d) for WSN and NPN in Emmental cheese. Nevertheless, it was surprising that the regions did not have prime importance in the NPN prediction model (Figure 4c).

The ammoniac regression coefficient distribution (Figure 4d) showed important bands at 1,430 to 1,390 $\mathrm{cm}^{-1}$ associated with ammonium ion (Coates, 2000) and 1,100 to $1,000 \mathrm{~cm}^{-1}$ characteristic of ammonium salts.

The 1,500 to $1,400 \mathrm{~cm}^{-1}$ band was also an important zone for ASN, NPN, and $\mathrm{NH}_{4}{ }^{+}$determination. The studies for the determination of chemical parameters in Emmental cheeses by infrared spectroscopy have brought to the fore the importance of the same spectral regions (Karoui et al., 2006c); no assignments were made for this zone.

The regression coefficient distribution for lactose showed that the 1,200 to $950 \mathrm{~cm}^{-1}$ spectral band was 
a) DM, g/100 g of cheese
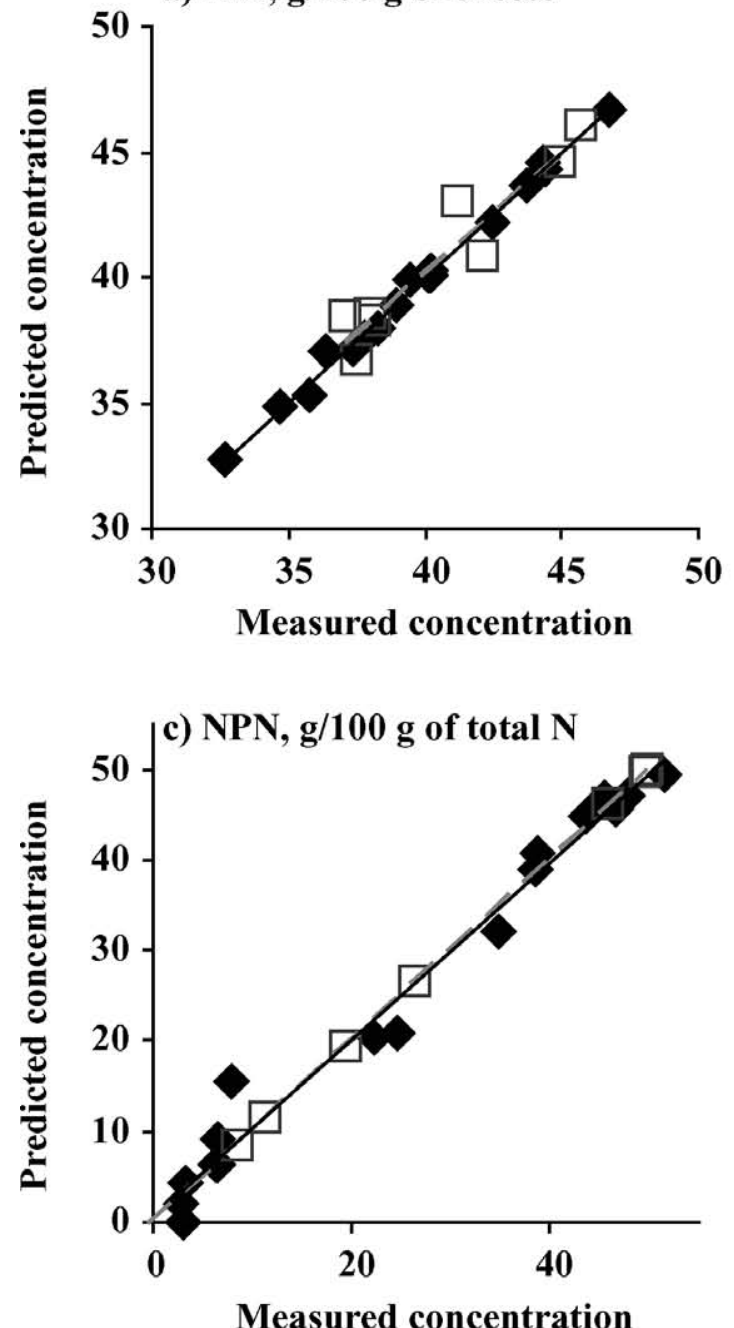

e) Lactose, mmol/kg of DM

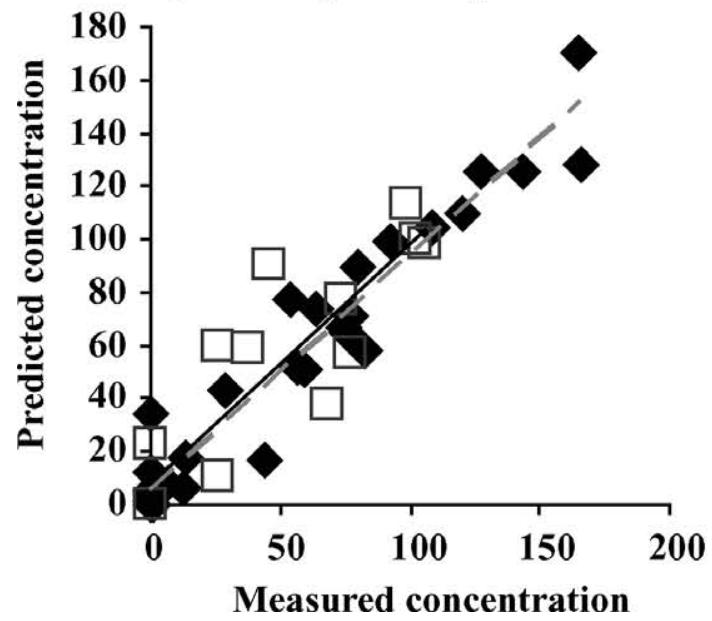

b) ASN, g/100 g of total $\mathrm{N}$

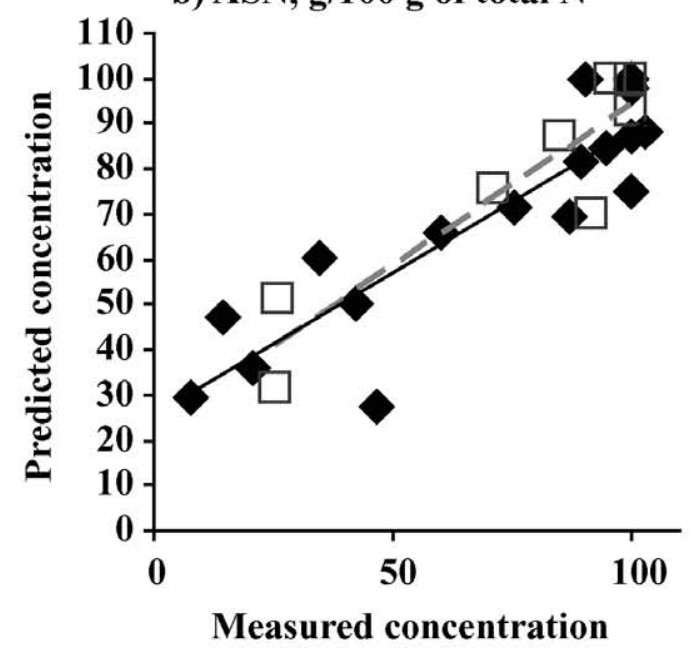

d) $\mathrm{NH}_{4}{ }^{+}, \mathrm{mmol} / \mathrm{kg}$ of $\mathrm{DM}$
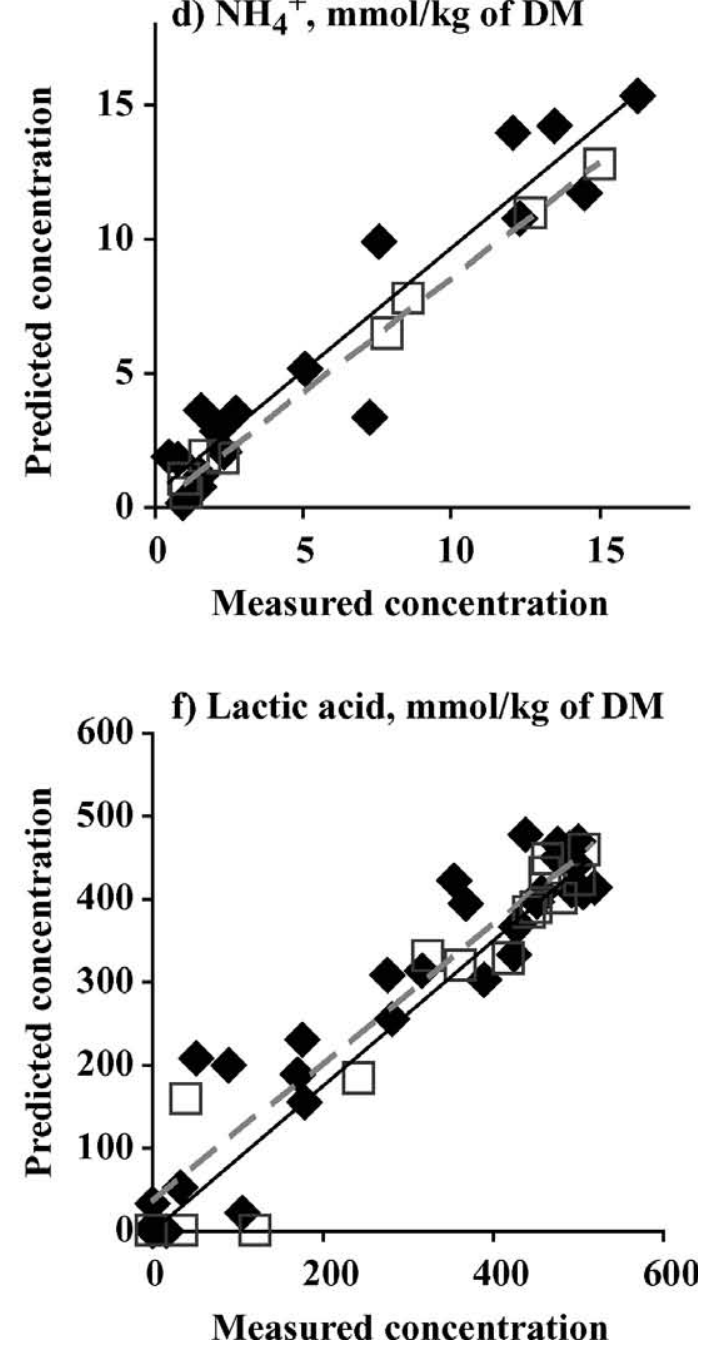

Figure 3. Partial least squares regression (PLS) plots established between measured and predicted values: a) DM (g/100 g of cheese), b) acid-soluble nitrogen (ASN; g/100 g of total N), c) NPN (g/100 g of total N), d) $\mathrm{NH}_{4}{ }^{+}(\mathrm{mmol} / \mathrm{kg}$ of DM); e) lactose (mmol/kg of DM); f) lactic acid $(\mathrm{mmol} / \mathrm{kg}$ of $\mathrm{DM}) ;-$ and $\diamond=$ calibration data; - - - and $\diamond=$ validation data. 
a)

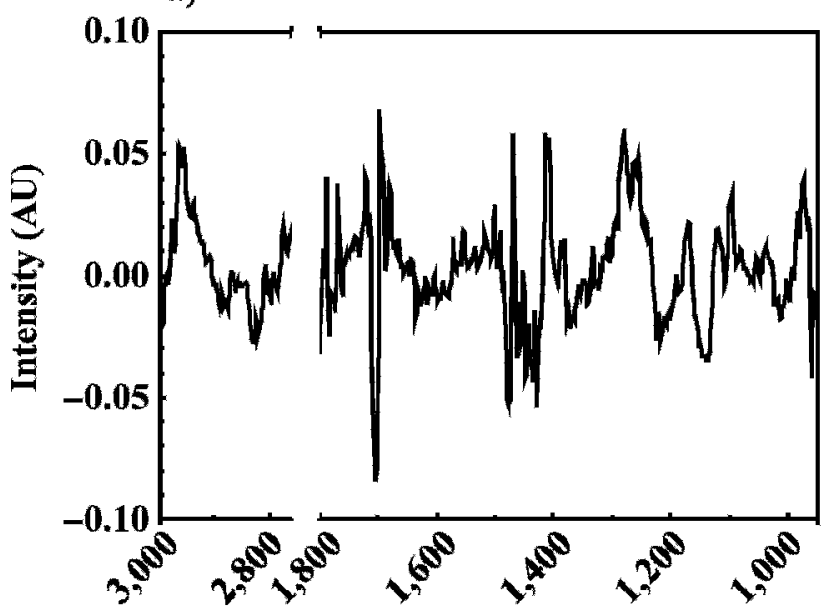

c)

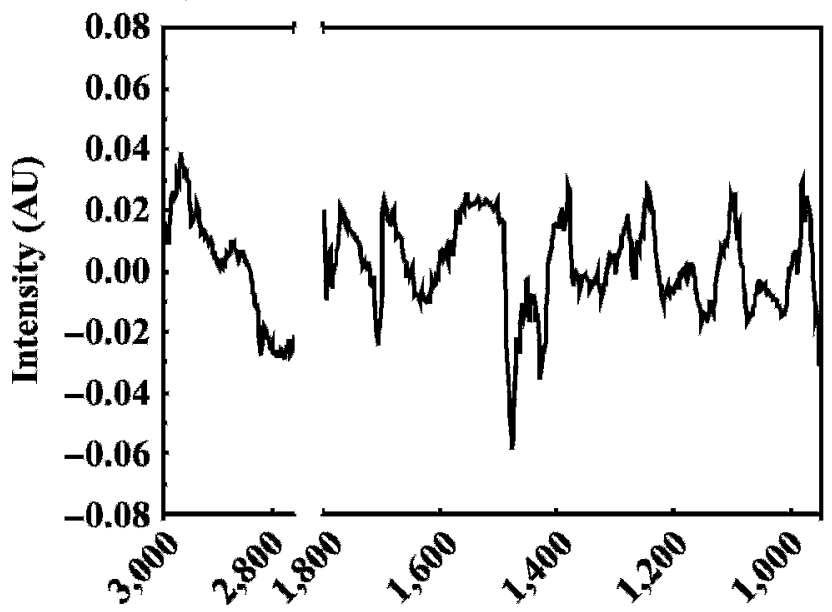

e)

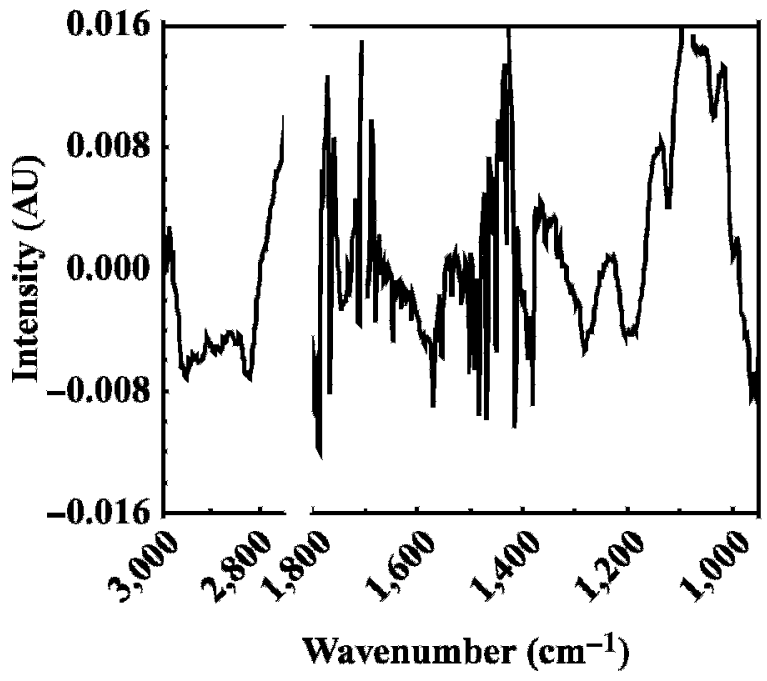

b)

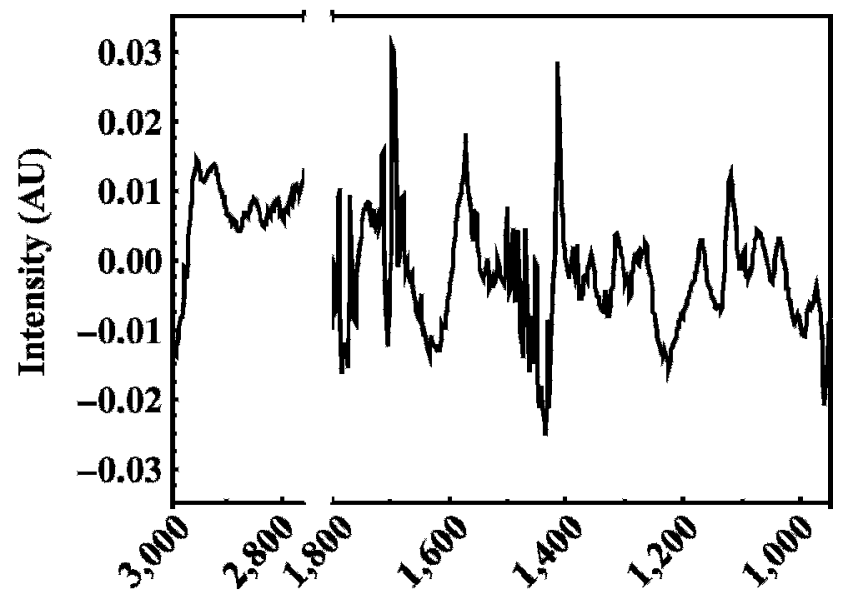

d)

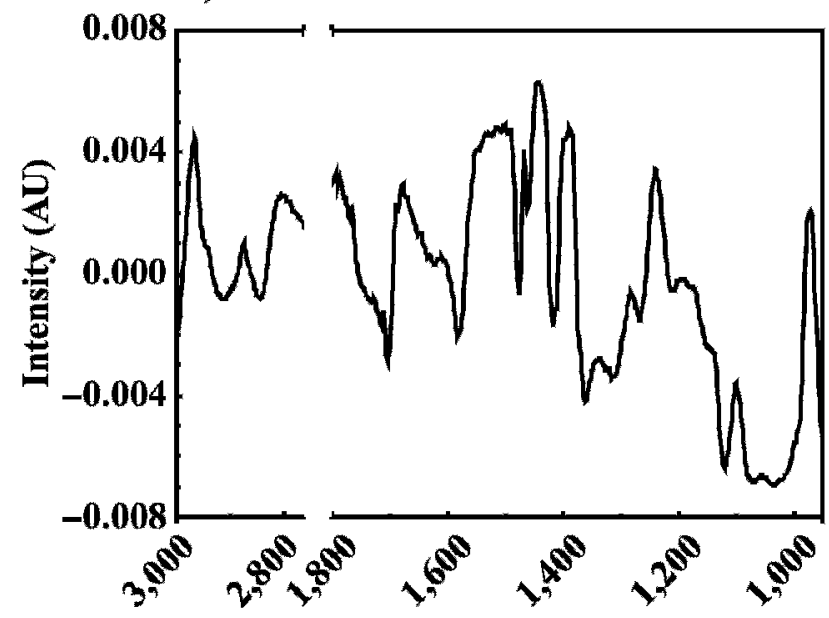

f)

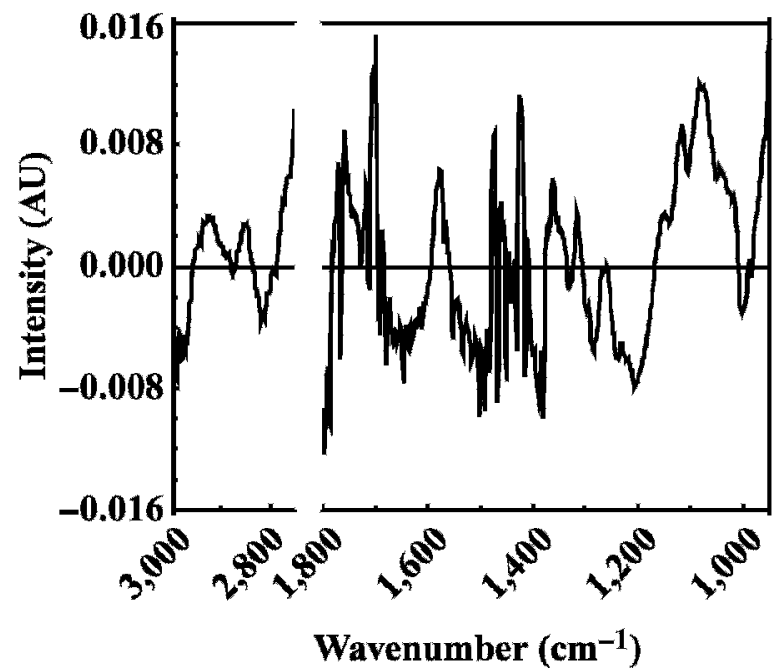

Figure 4. Partial least squares (PLS) regression coefficients over the infrared spectral regions $\left(3,000\right.$ to $2,800 \mathrm{~cm}^{-1}$ and 1,800 to 950 $\mathrm{cm}^{-1}$ wavenumbers; intensity in arbitrary units): a) DM, b) acid-soluble nitrogen (ASN), c) NPN, d) $\mathrm{NH}_{4}^{+}$, e) lactose, and f) lactic acid. 
the most efficient region (Figure $4 \mathrm{e}$ ). This region is in agreement with the bands assigned to lactose.

Regarding lactic acid, the regression coefficient distributions indicated that the 1,150 to $1,000 \mathrm{~cm}^{-1}, 1,450$ to $1,400 \mathrm{~cm}^{-1}$, and 1,600 to $1,550 \mathrm{~cm}^{-1}$ regions were the most interesting spectral zones (Figure 4f). These observations were in agreement with the absorption bands known for lactic acid.

\section{CONCLUSIONS}

The results obtained in this study demonstrated that FTIR is a suitable method to follow the changes of some physicochemical parameters throughout ripening in Camembert-type cheeses. The PLS regression between physicochemical and spectral data showed that FTIR is a good method to predict DM, lactose, lactic acid, ASN, NPN, and $\mathrm{NH}_{4}^{+}$values throughout ripening (from $\mathrm{d} 1$ to 27); the model obtained for $\mathrm{pH}$ is less accurate. Fourier transform infrared spectroscopy has possibilities as a fast and inexpensive method to predict the glycolysis and proteolysis status during Camembert cheese ripening. It could be helpful for the cheese maker in estimating the level of cheese ripening. However, a larger study will be necessary to confirm these results on soft mold-ripened cheese and could be extended to other types of cheeses.

\section{ACKNOWLEDGMENTS}

S. T. Martín del Campo would like to thank the Consejo Nacional de Ciencia y Tecnología (CONACyT) for her PhD scholarship and the Programa de Cooperación de Posgrados (PCP) México-France for support of her thesis project. Thanks to the Centro de Investigación y Asistencia en Tecnología y Diseño del Estado de Jalisco (CIATEJ) for its support to this thesis project, through Ricardo Cosío-Ramírez, who is a researcher in this institution.

\section{REFERENCES}

Ardö, Y., and A. Polychroniadou. 1999. Laboratory Manual for Chemical Analysis of Cheese. Ed. Office for Official Publications of the European Communities, Luxembourg, Luxembourg.

Bertrand, D. 2000. Prétraitement des données spectrales. Pages $351-$ 370 in La spectroscopie infrarouge et ses applications analytiques. D. Bertrand and E. Dufour, ed. Lavoisier Tec \& Doc, Paris, France.

Cadet, F., M. Safar, and E. Dufour. 2000. Glucides. Pages 172-195 in La spectroscopie infrarouge et ses applications analytiques. D. Bertrand and E. Dufour, ed. Lavoisier Tec \& Doc, Paris, France.

Chen, M., J. Irudayaraj, and D. J. McMahon. 1998. Examination of full fat and reduced fat Cheddar cheese during ripening by Fourier transform infrared spectroscopy. J. Dairy Sci. 81:2791-2797.

Christensen, T. M. I. E., A. M. Bech, and H. Werner. 1991. Methods for crude fractionation (extraction and precipitation) of nitrogen components in cheese. Bull. IDF 261:4-9.
Coates, J. 2000. Interpretation of infrared spectra, a practical approach. Pages 10815-10837 in Encyclopedia of Analytical Chemistry. R. A. Meyers, ed. John Wiley \& Sons Ltd., Chichester, UK.

Defernez, M., and E. K. Kemsley. 1997. The use and misuse of chemometrics for treating classification problems. Trends Anal. Chem. $16: 216-221$

Dousseau, F., M. Therrien, and M. Pézolet. 1989. On the spectral subtraction of water from the FT-IR spectra of aqueous solutions of proteins. Appl. Spectrosc. 43:538-542.

Downey, G., E. Sheehan, C. Delahunty, D. O'Callaghan, T. Guinee, and D. V. Howard. 2005. Prediction of maturity and sensory attributes of Cheddar cheese using near-infrared spectroscopy. Int. Dairy J. 15:701-709.

Engel, E., C. Tournier, C. Salles, and J. L. Le Quere. 2001. Evolution of the composition of a selected bitter Camembert cheese during ripening: Release and migration of taste-active compounds. J. Agric. Food Chem. 49:2940-2947.

Etzion, Y., R. Linker, U. Cogan, and I. Shmulevich. 2004. Determination of protein concentration in raw milk by mid-infrared Fourier transform infrared/attenuated total reflectance spectroscopy. J. Dairy Sci. 87:2779-2788.

Fallico, V., P. L. H. McSweeney, K. J. Siebert, J. Horne, S. Carpino, and G. Licitra. 2004. Chemometric analysis of proteolysis during ripening of Ragusano cheese. J. Dairy Sci. 87:3138-3152.

Gorostiza, A., A. J. Cichoscki, A. T. Valduga, E. Valduga, A. Bernardo, and J. M. Fresno. 2004. Changes in soluble nitrogenous compounds, caseins and free amino acids during ripening of artisanal Prato cheese; a Brazilian semi-hard cows variety. Food Chem. 85:407-414.

Grappin, R., D. Lefier, and G. Mazerolles. 2000. Analyse du lait et des produits laitiers. Pages 497-540 in La spectroscopie infrarouge et ses applications analytiques. D. Bertrand and E. Dufour, ed. Lavoisier Tec \& Doc, Paris, France.

Karoui, R., G. Mazerolles, and E. Dufour. 2003. Spectroscopic techniques coupled with chemometric tools for structure and texture determinations in dairy products. Int. Dairy J. 13:607-620.

Karoui, R., A. Mouazen, E. Dufour, L. Pillonel, E. Schaller, D. Picque, J. Baerdemaeker, and J. Bosset. 2006a. A comparison and joint use of NIR and MIR spectroscopic methods for the determination of some parameters in European Emmental cheese. Eur. Food Res. Technol. 223:44-50.

Karoui, R., A. Mouazen, E. Dufour, R. Schoonheydt, and J. Baerdemaeker. 2006b. A comparison and joint use of VIS-NIR and MIR spectroscopic methods for the determination of some chemical parameters in soft cheeses at external and central zones: A preliminary study. Eur. Food Res. Technol. 223:363-371.

Karoui, R., A. M. Mouazen, E. Dufour, L. Pillonel, D. Picque, J. D. Baerdemaeker, and J. O. Bosset. 2006c. Application of the MIR for the determination of some chemical parameters in European Emmental cheeses produced during summer. Eur. Food Res. Technol. 222:165-170.

Karoui, R., A. M. Mouazen, E. Dufour, L. Pillonel, D. Picque, J. O. Bosset, and J. De Baerdemaeker. 2006d. Mid-infrared spectrometry: A tool for the determination of chemical parameters in Emmental cheeses produced during winter. Lait 86:83-97.

Leclercq-Perlat, M. N., F. Buono, D. Lambert, E. Latrille, H. E. Spinnler, and G. Corrieu. 2004. Controlled production of Camemberttype cheeses. Part I: Microbiological and physicochemical evolutions. J. Dairy Res. 71:346-354.

Leclercq-Perlat, M. N., A. Oumer, J. L. Bergère, H. E. Spinnler, and G. Corrieu. 1999. Growth of Debaryomyces hansenii on a bacterial surface-ripened soft cheese. J. Dairy Res. 66:271-281.

Leclercq-Perlat, M. N., A. Oumer, F. Buono, J. L. Bergère, H. E. Spinnler, and G. Corrieu. 2000. Behavior of Brevibacterium linens and Debaryomyces hansenii as ripening flora in controlled production of soft smear cheese from reconstituted milk: Protein degradation. J. Dairy Sci. 83:1674-1683.

Martín Del Campo, S. T., D. Picque, R. Cosío-Ramírez, and G. Corrieu. 2007. Middle infrared spectroscopy characterization of ripening stages of camembert-type cheeses. Int. Dairy J. 17:835-845.

McQueen, D. H., R. Wilson, A. Kinnunen, and E. P. Jensen. 1995. Comparison of two infrared spectroscopic methods for cheese analysis. Talanta 42:2007-2015. 
Mouazen, A. M., J. De Baerdemaeker, and H. Ramon. 2005. Towards development of on-line soil moisture content sensor using a fibretype NIR spectrophotometer. Soil Tillage Res. 80:171-183.

Picque, D., D. Lefier, R. Grappin, and G. Corrieu. 1993. Monitoring of fermentation by infrared spectrometry alcoholic and lactic fermentations. Anal. Chim. Acta 279:67-72.

Poveda, J. M., L. Cabezas, and P. L. H. McSweeney. 2004. Free amino acid content of Manchego cheese manufactured with different starter cultures and changes throughout ripening. Food Chem. 84:213-218.

Powell, J. R., F. M. Wasacz, and R. J. Jakobsen. 1986. An algorithm for the reproducible spectral subtraction of water from the FT-IR spectra of proteins in dilute solutions and adsorbed monolayers. Appl. Spectrosc. 40:339-344.

Pripp, A. H., S. U. Rehman, P. L. H. McSweeney, and P. F. Fox. 1999. Multivariate statistical analysis of peptide profiles and free amino acids to evaluate effects of single-strain starters on proteolysis in miniature Cheddar-type cheeses. Int. Dairy J. 9:473-479.

Rodriguez-Saona, L. E., N. Koca, W. J. Harper, and V. B. Alvarez. 2006. Rapid determination of Swiss cheese composition by Fourier transform infrared/attenuated total reflectance spectroscopy. J. Dairy Sci. 89:1407-1412.

Skeie, S., G. Feten, T. Almoy, H. Ostlie, and T. Isaksson. 2006. The use of near infrared spectroscopy to predict selected free amino acids during cheese ripening. Int. Dairy J. 16:236-242. 